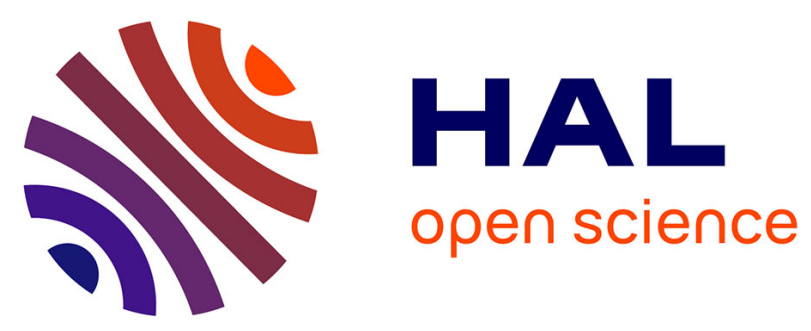

\title{
SUBJECTIVE QUALITY OF SVC-CODED VIDEOS WITH DIFFERENT ERROR-PATTERNS CONCEALED USING SPATIAL SCALABILITY
}

\author{
Yohann Pitrey, Ulrich Engelke, Patrick Le Callet, Marcus Barkowsky, \\ Romuald Pépion
}

\section{To cite this version:}

Yohann Pitrey, Ulrich Engelke, Patrick Le Callet, Marcus Barkowsky, Romuald Pépion. SUBJECTIVE QUALITY OF SVC-CODED VIDEOS WITH DIFFERENT ERROR-PATTERNS CONCEALED USING SPATIAL SCALABILITY. Third European Workshop on Visual Information Processing (EUVIP), Jul 2011, Paris, France. paper number 67. hal-00608300

\section{HAL Id: hal-00608300 https://hal.science/hal-00608300}

Submitted on 12 Jul 2011

HAL is a multi-disciplinary open access archive for the deposit and dissemination of scientific research documents, whether they are published or not. The documents may come from teaching and research institutions in France or abroad, or from public or private research centers.
L'archive ouverte pluridisciplinaire HAL, est destinée au dépôt et à la diffusion de documents scientifiques de niveau recherche, publiés ou non, émanant des établissements d'enseignement et de recherche français ou étrangers, des laboratoires publics ou privés. 


\section{Subjective quality of SVC-coded videos with different error-patterns concealed using spatial scalability}

Y. Pitrey, U. Engelke, M. Barkowsky, R. Pepion, P. Le Callet

Polytech'Nantes - IRCCyN UMR CNRS 6597

LUNAM - Universite de Nantes

EUVIP 2011, Paris 


\section{Network impairments and video transmission}

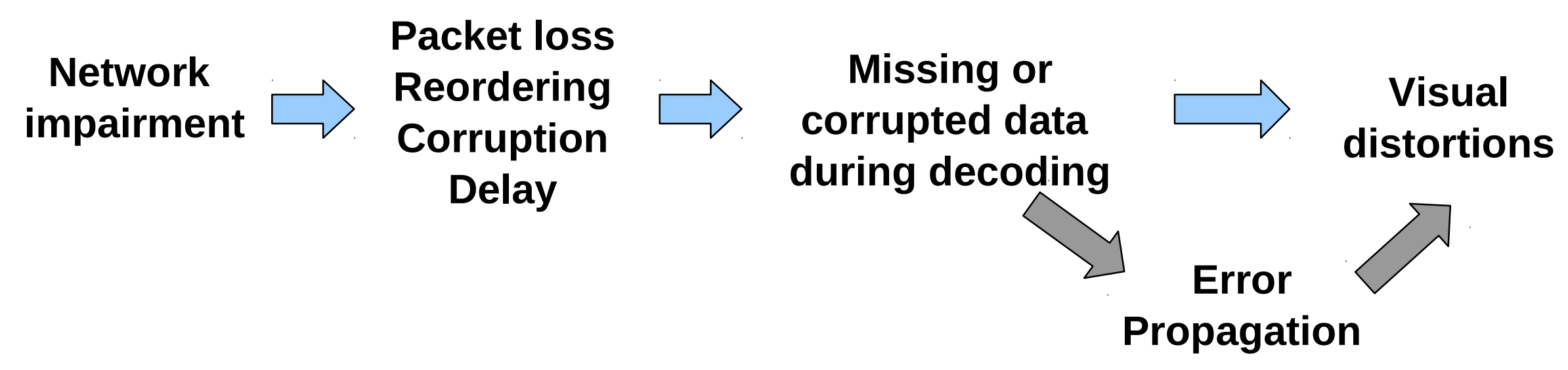

How to minimize visual distortions?

- Stream protection

- Error-concealment 


\section{SVC-based error-concealment}

- 2 SVC spatial layers

- BL : $320 \times 240$

- EL : $640 \times 480$

- Loss only in EL

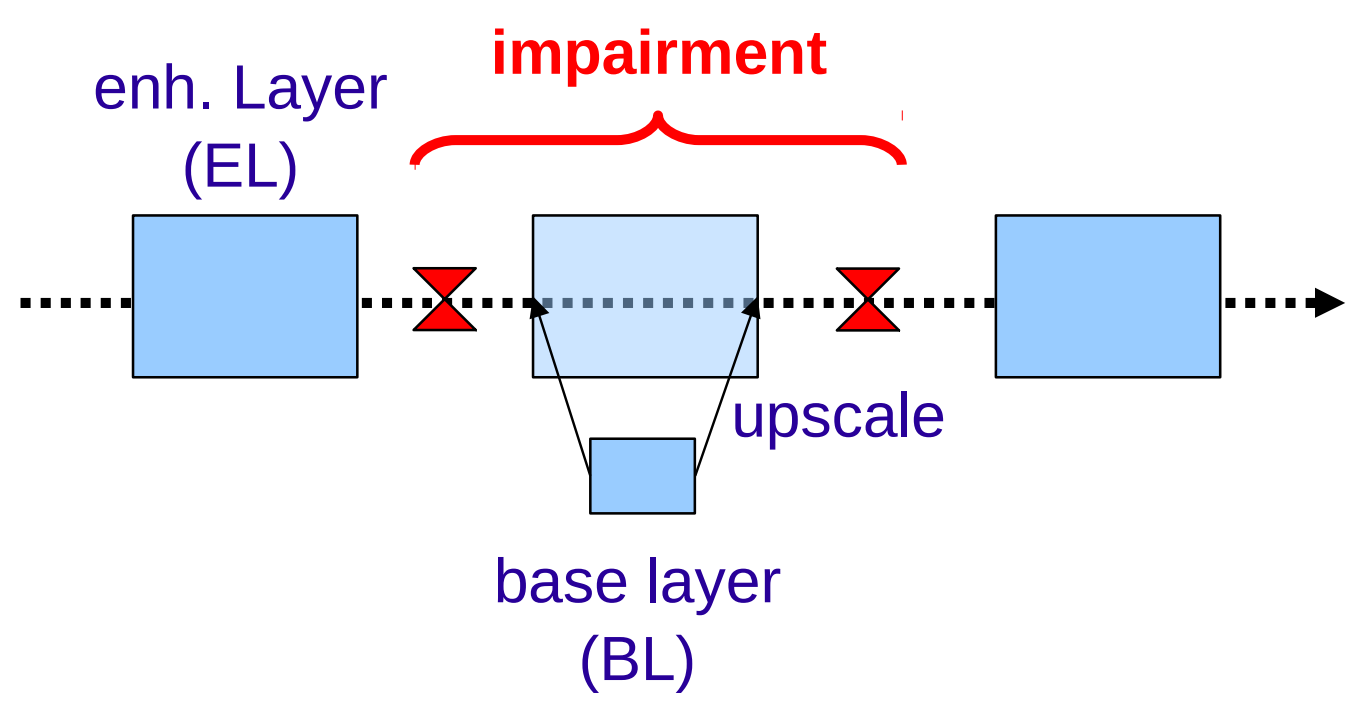

- Hypothesis

- No loss in base layer

(base layer protection) 


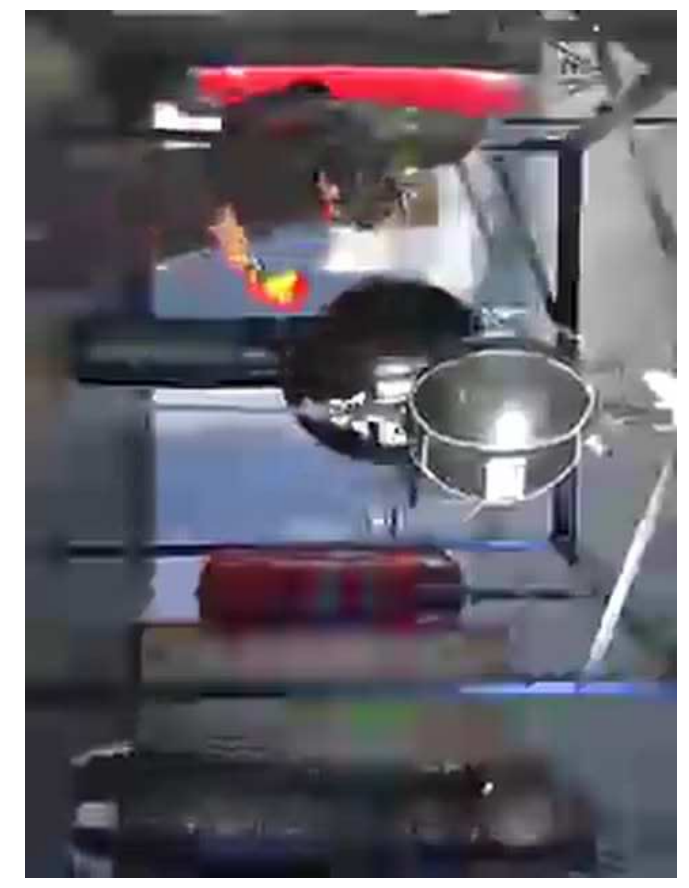

upscaled base layer

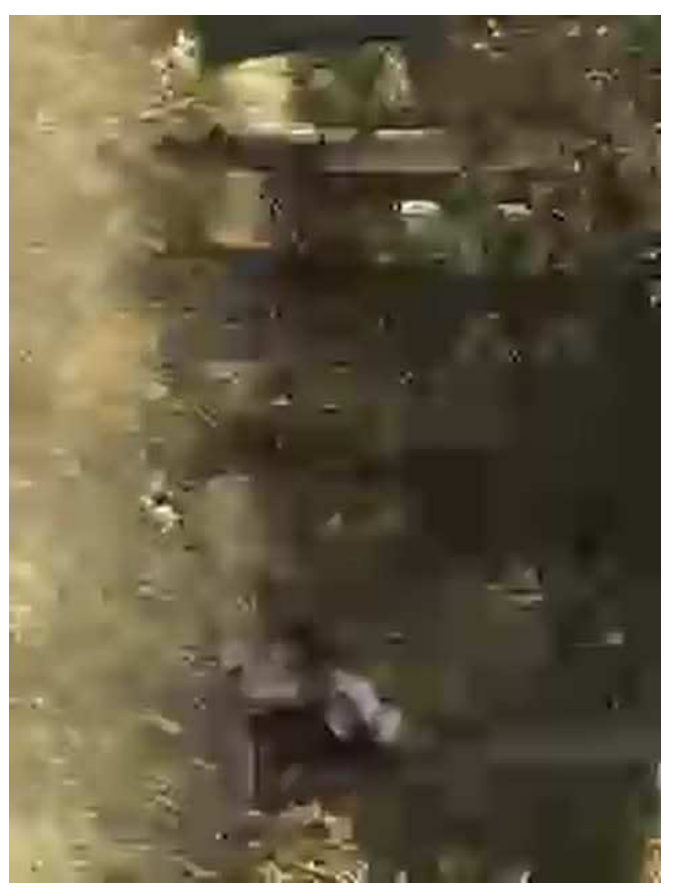

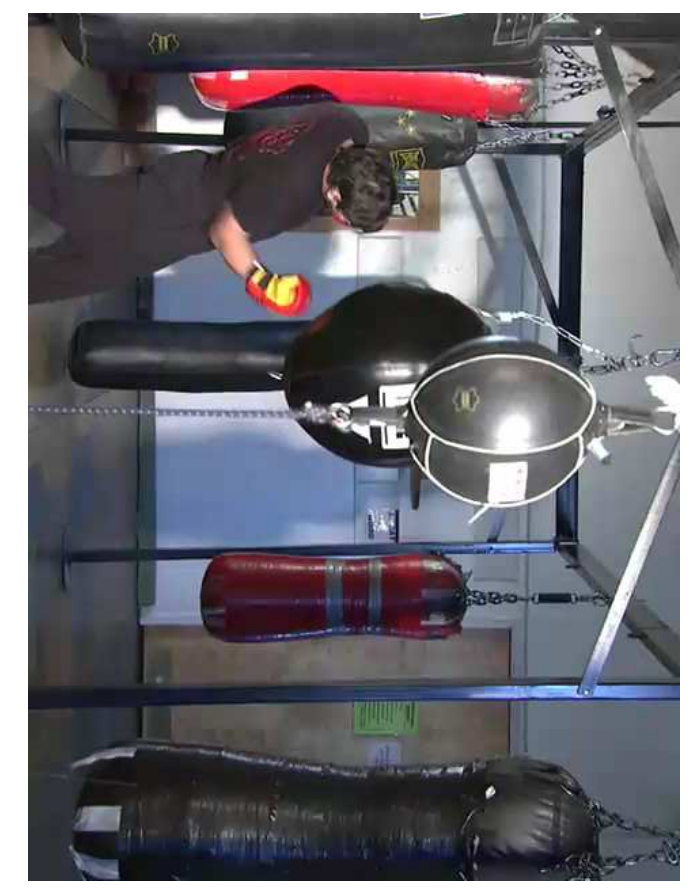

enhancement layer

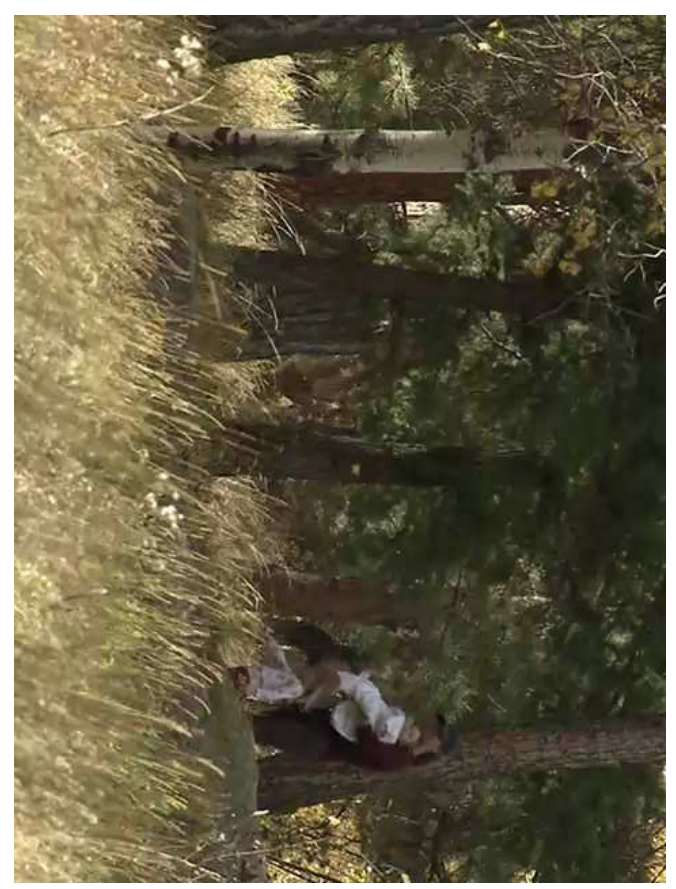

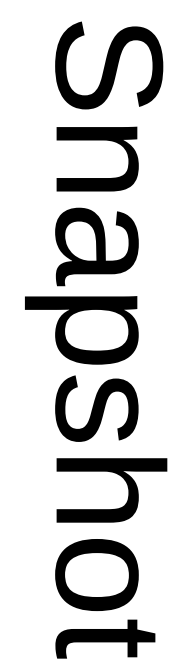

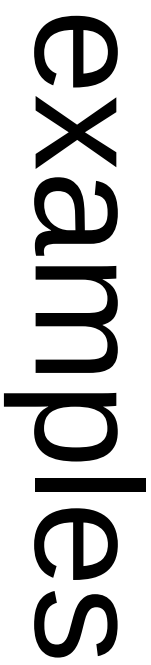


Factors having an impact on perceived quality

Length of impairment

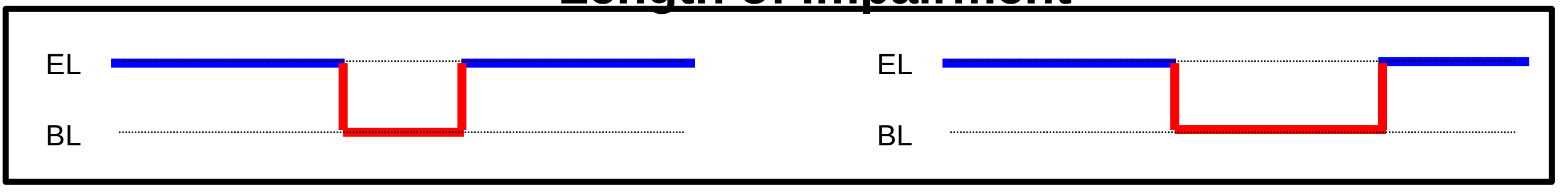

Number of impairments

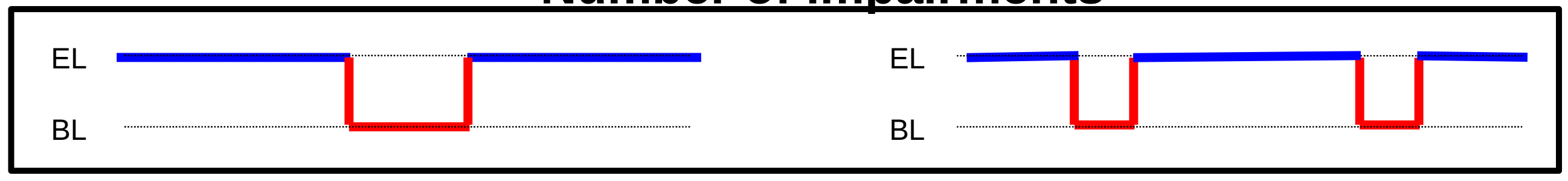

Interval between impairments

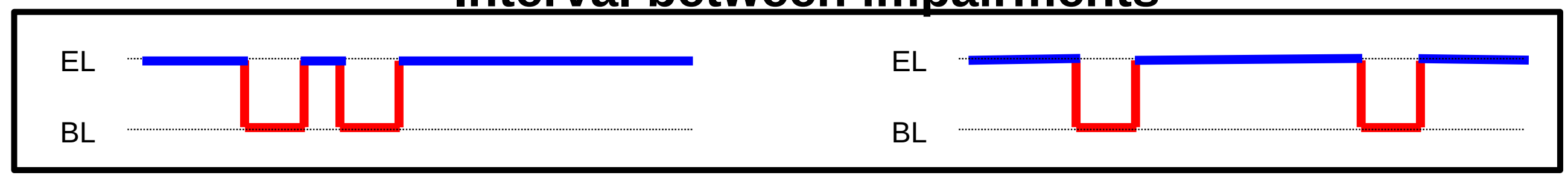

\section{Base Layer Quality}

EL
BL

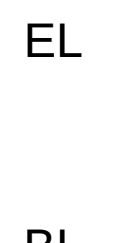

$B L$ 


\section{Experimental setup}

- Content generation :

- 9 video contents $12 \mathrm{sec}, 30 \mathrm{fps}$

- 26 impairment patterns

+1 reference

- SVC reference encoder JSVM V9.18

- Lanczos upscaler QVGA $\rightarrow$ VGA

- Impairment simulated on the decoded videos (YUV)

- first and last second not impaired
- Test conditions :

- ACR 5-levels scale (ITU-T P.910)

- Standard viewing conditions (ITU-R BT.500)

- 42" reference screen

- 28 naïve viewers

- 2 sessions of $45 \mathrm{~min}$ with 5 min break after 20 min 


\section{Impairment patterns}

- Systematic approach :

Several conditions for each influence factor

- Considered values for each influence factor :

- Length : $\quad\{2,8,16,32,64,128\}$

- Number : $\quad\{1,2,3,4\}$

- Interval: $\quad\{8,16,32,64,128\}$

- BL Quality : QP $=\{38,44\}$ 


\section{Experimental results}

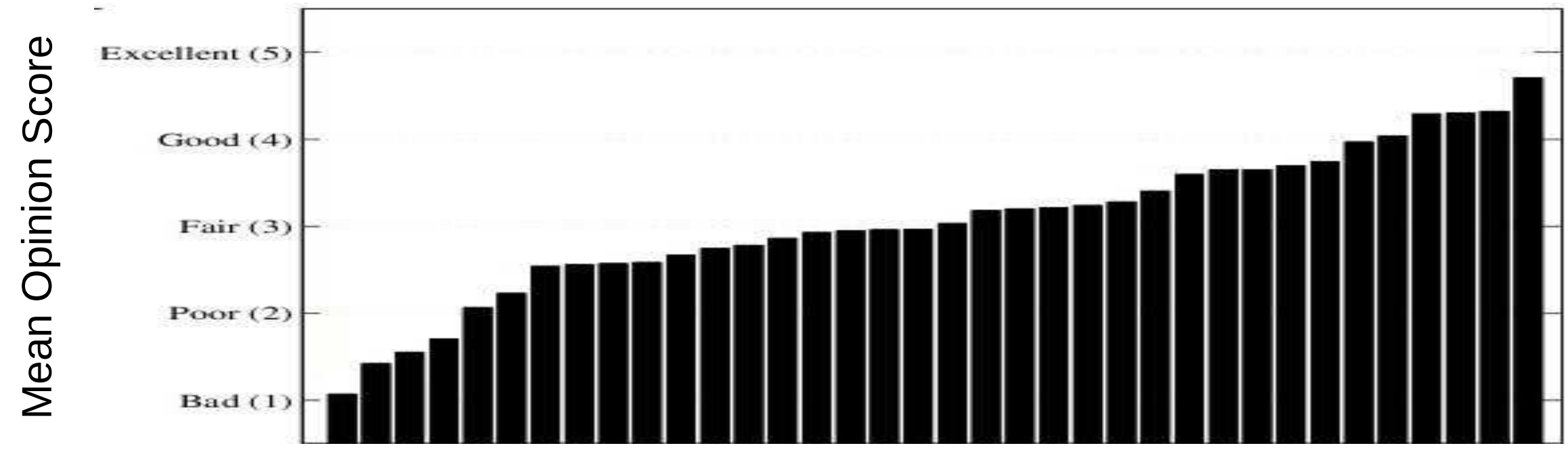

Tested conditions

- Wide and balanced range of qualities

- Statistical significance analysis :

- Student-t test

- 95\% intervals of confidence (displayed on next slides) 


\section{Impact of base layer quality}

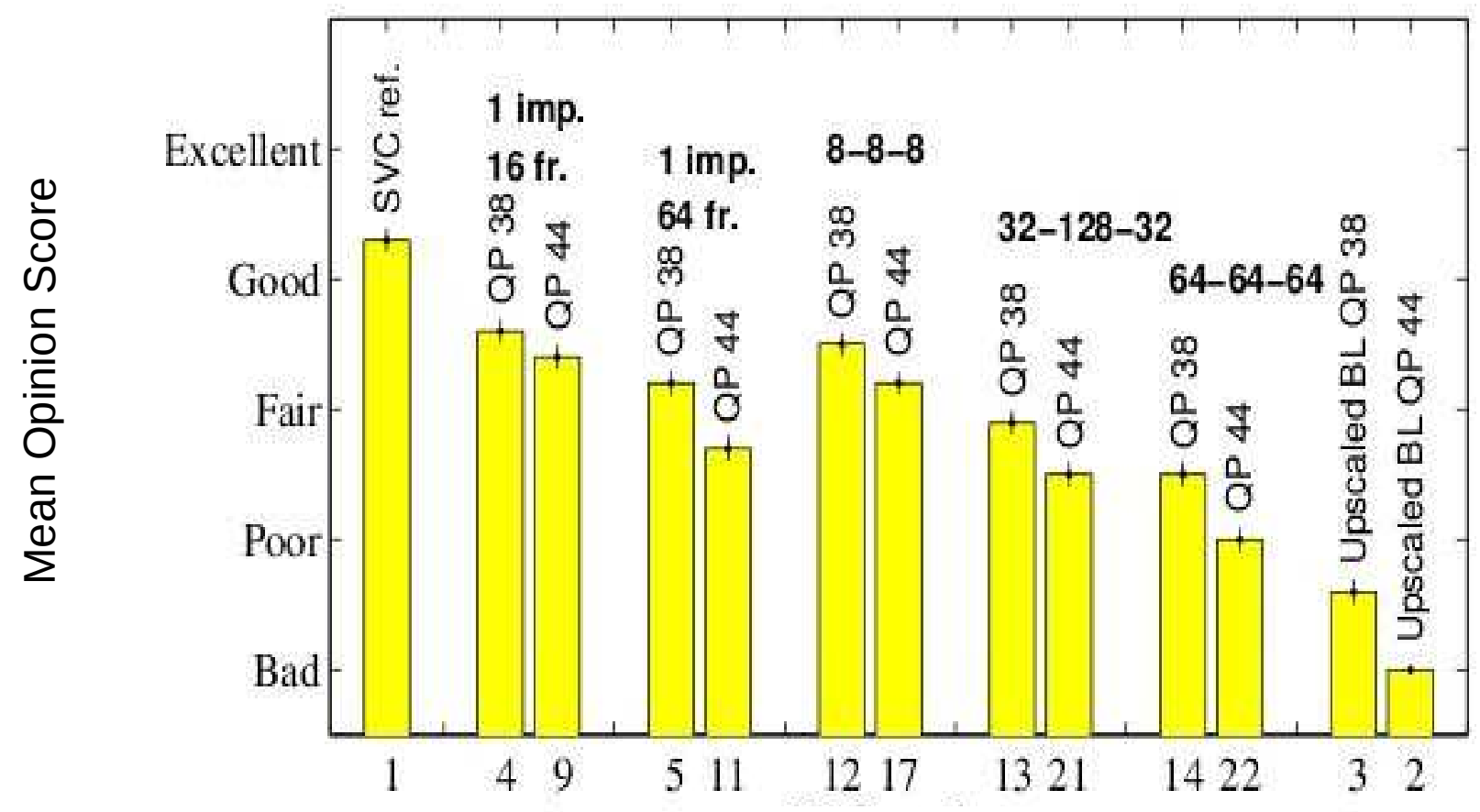

95\% intervals of confidence displayed as error bars

- Significant impact of base layer QP

- Stronger impact for long impairments 


\section{Impact of length of impairments}

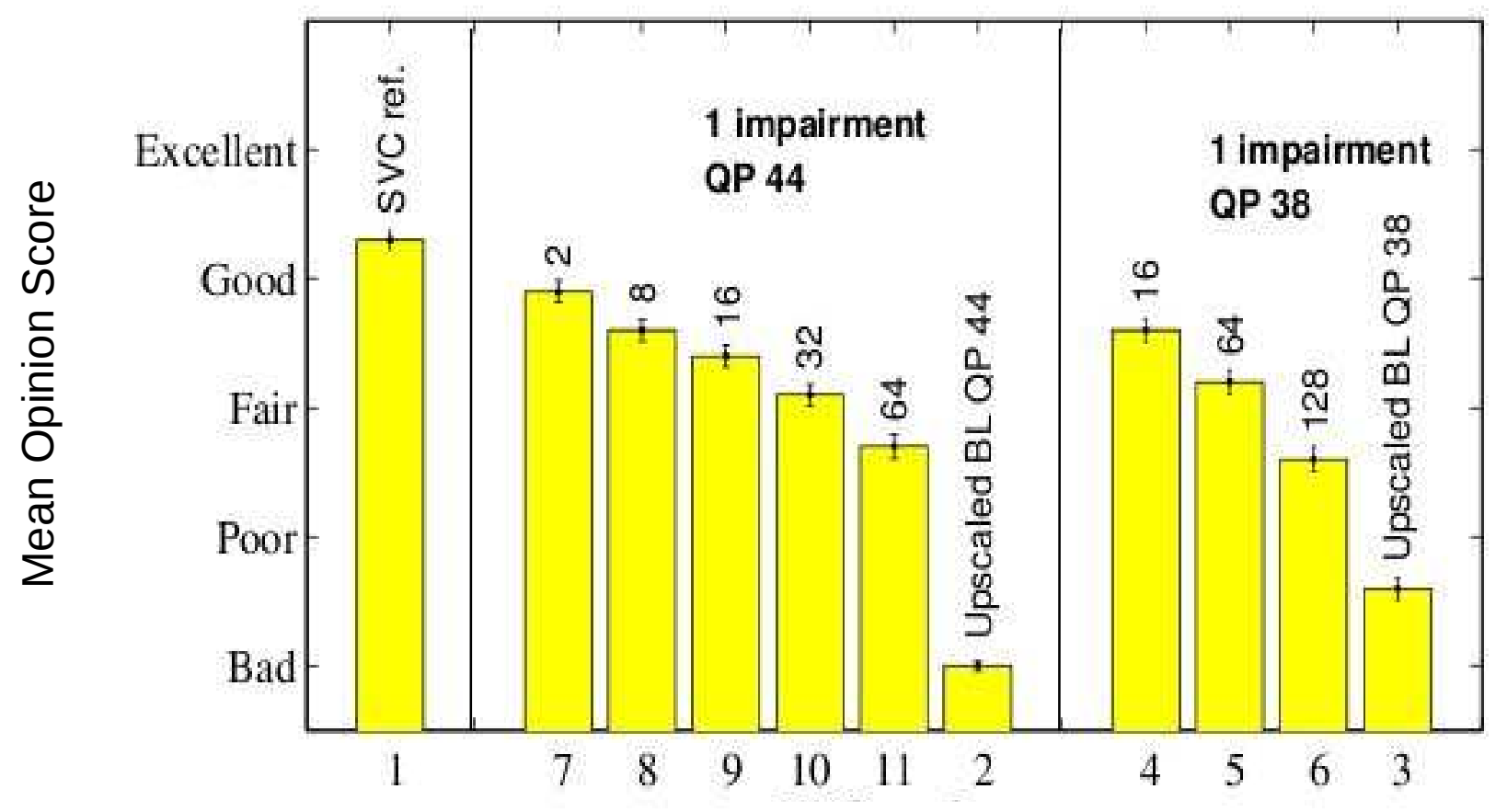

- Significant impact

- Linear decrease of quality / exp. increase of duration

- Slope of the decrease depends on base layer QP 


\section{Impact of number of impairments}

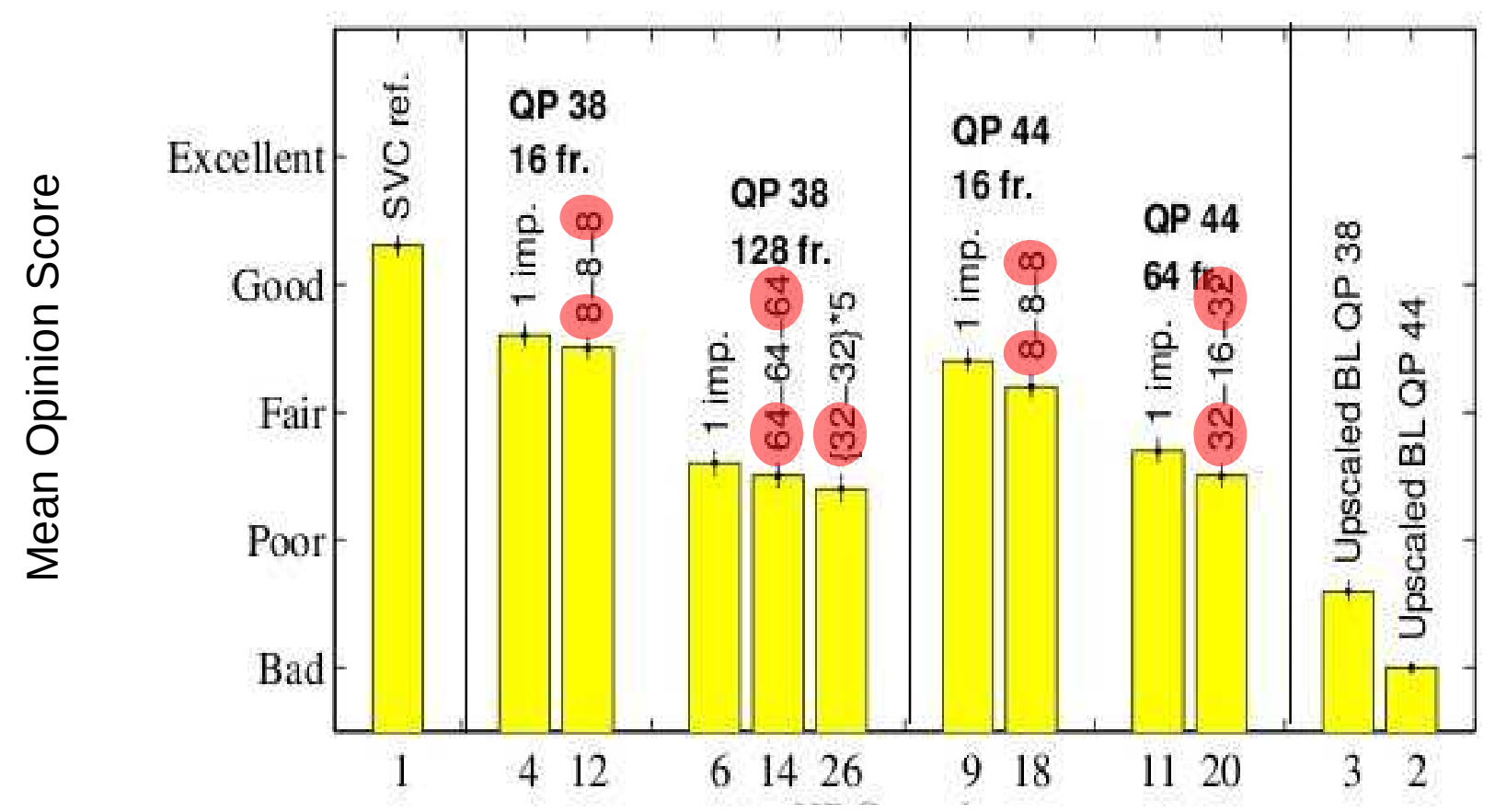

- Significant but limited impact

- Depends on base layer QP 


\section{Impact of interval between impairments}

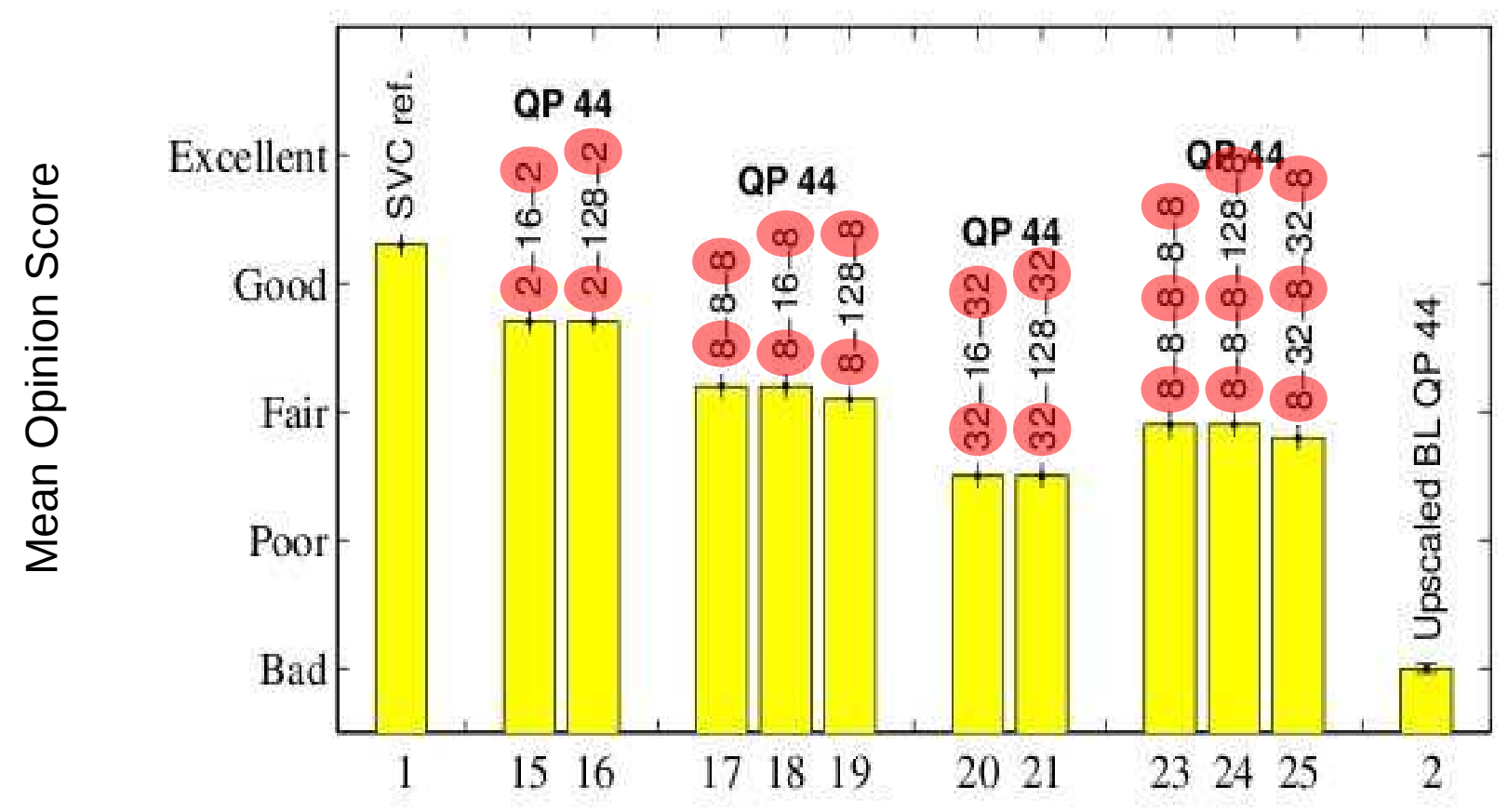

- No significant impact ! 


\section{Conclusion}

- Ordering the influence on quality of the 4 factors :

1. quality of the base layer $>2$. length of impairments

3. number of impairments $>4$. interval between impairments

- Modeling the influence of the parameters

- Linear decrease with the length of impairments

- Significant dependence on the base layer coding quality

- Joint impact of factors

- To be investigated :

- Influence of the source content

- Bit-rate constraints

- Publication of video database 


\section{Thank you for your attention}

\section{Questions?}




\section{Impact of impairments on perceived quality}

Our goal : Study the factors that influence visual quality in this context

\section{4 factors :}

- Impairments distribution :

- Length of impairments (cumulated)

- Number of impairments

- Interval between impairments

- SVC error concealment :

- Quality of the base layer (QP) 